\title{
Functional training added to intradialytic cycling lowers low-density lipoprotein cholesterol and improves dialysis adequacy: a randomized controlled trial
}

\author{
Špela Bogataj ${ }^{1,2}$, Jernej Pajek ${ }^{1,3}$, Jadranka Buturović Ponikvar ${ }^{1,3}$ and Maja Pajek ${ }^{2^{*}}$ (i)
}

\begin{abstract}
Background: Exercise has various positive effects on hemodialysis patients. However, there is no clear evidence which type of exercise yields better results. This study aimed to determine the effects of guided functional training added to the intradialytic cycling on dialysis adequacy and biochemical parameters in hemodialysis patients. Additionally, we aimed to investigate if patients could transfer functional exercise to an unsupervised home environment and retain gained improvements.
\end{abstract}

Methods: Randomization was done to a functional training intervention group (INT) $(n=20)$ or intradialytic cycling control group (CON) $(n=20)$. The INT attended a pre-dialysis functional training in the first 8 weeks. In the second 8 weeks, they performed functional exercises at unsupervised home environment on non-dialysis days. During the whole study, both groups participated in the intradialytic cycling program.

Results: Both groups demonstrated a significant increase in dialysis adequacy $(\mathrm{Kt} / \mathrm{N})$ in the eight $(0.15,95 \% \mathrm{Cl} 0.06$ to $0.24 ; p=0.003$ for INT and $0.21,95 \% \mathrm{Cl} 0.11$ to $0.3 ; p<0.001$ for CON $)$ and the 16 th study week $(0.13,95 \% \mathrm{Cl} 0.03$ to $0.24 ; p=0.017$ for INT and $0.13,95 \% \mathrm{Cl} 0.03$ to 0.22 ; $p=0.013$ for CON) compared to their baseline values with no significant between-group differences. At week eight, the total cholesterol was significantly lowered in the INT $(-0.34 \mathrm{mmol} / \mathrm{L}, 95 \% \mathrm{Cl}-0.6$ to $-0.07 ; p=0.016)$ and remained lower at week $16(-0.32 \mathrm{mmol} / \mathrm{L}, 95 \% \mathrm{Cl}-0.64$ to $-0.01 ; p=0.049)$ with no significant changes in the CON. Low-density lipoprotein levels in the INT were significantly reduced after 8 weeks $(-0.35 \mathrm{mmol} / \mathrm{L}, 95 \% \mathrm{Cl}-0.64$ to $-0.06 ; p=0.022)$ and remained reduced after 16 weeks $(-0.28 \mathrm{mmol} / \mathrm{L}, 95 \% \mathrm{Cl}-0.52$ to $-0.03 ; p=0.030)$. There were no significant differences found for albumin, high-density lipoprotein cholesterol, triglycerides, C-reactive protein, and hemoglobin in both groups.

Conclusions: We demonstrated that functional training added to intradialytic cycling improved lipid profile and dialysis adequacy. Additionally, the effects of the unsupervised, home-based program were preserved during the second study phase. This study supports the assumption that combined training is more effective compared to solely intradialytic exercise.

Trial registration: ClinicalTrials.Gov, NCT03334123. Registered 07 November 2017.

Keywords: Exercise, Hemodialysis, CKD, Intervention, Health promotion

\footnotetext{
* Correspondence: maja.pajek@fsp.uni-lj.si

¿University of Ljubljana, Faculty of Sport, 1000 Ljubljana, Slovenia

Full list of author information is available at the end of the article
} 


\section{Background}

Chronic kidney disease (CKD) is an important and common cause of death with the increasing number of patients around the world [1]. CKD is related to obesity, type 2 diabetes, arterial hypertension and confers increased cardiovascular disease risk [2]. The majority of patients with moderate CKD die before they reach end-stage renal disease (ESRD) [3]. However, increased physical activity could have a survival benefit for CKD patients and subsequently reduce their death rate $[4,5]$.

Multiple studies [6-23] have investigated physical exercise interventions as a treatment for CKD. Although the adequacy of exercise modalities in these studies is inconsistent [24], Johansen \& Painter [25] have noted that physical exercise appears to be safe in the CKD population, with no single study reporting the worsening of kidney function. Moreover, several systematic reviews and metaanalyses published recently delivered the consensus that regular exercise is beneficial for patients in CKD stages 14 and in end-stage renal disease (CKD stage 5), with the majority of studies conducted in CKD stage 5 patients treated with hemodialysis (HD) [15, 26-31].

Intradialytic cycling performed during $\mathrm{HD}$ has been widely accepted as a beneficial exercise intervention due to its feasibility and improvements in physical performance $[6,7,32]$. However, integrating intradialytic cycling with an aerobic and resistance exercise program to increase the volume and quality of exercise (e.g., functional training) could improve hematological indexes, healthrelated quality of life, and reduce inflammatory cytokines and depression [17]. Studies have also provided evidence of intradialytic exercise programs enabling improvement in urea clearance (Kt/V) [16], reduced need for antihypertensive medications [18], an increase in hemoglobin concentration, and improvement in lipid metabolism [19]. It is well documented that people with CKD have a higher risk of developing cardiovascular decease [33]. Therefore, normalisation or at least aiming to reduce the elevated levels of low-density lipoprotein (LDL) should be of great importance for CKD patients. However, the impact of exercise interventions for lowering LDL cholesterol is not sufficiently defined [21-23]. Goldberg et al. [22] and more recently Cheema et al. [21] showed reduced levels of LDL cholesterol in HD patients, while De Moura et al. [23] found increased levels of LDL and triglycerides following aerobic exercise during HD. Therefore, we need additional evidence about effectiveness of exercise interventions in dialysis patients targeting LDL cholesterol levels to prevent the development of cardiovascular decease.

It is stated that an HD treatment is "adequate« when patients have a good nutritional condition, are cleared from uremia symptoms, have normal blood pressure, satisfactory red blood cell production, and are prevented from neuropathy development [34]. The most frequently used small solute HD adequacy indicator is the urea Kt/ $\mathrm{V}$. It stands for the product of urea clearance and time of HD procedure per unit of urea distribution volume [35]. A higher Kt/V represents better small solute removal, which is linked to lower organ toxicity. Exercise training could improve $\mathrm{Kt} / \mathrm{V}$ by reducing the postdialysis rebound in concentration of uremic solutes [36]. The reduced urea rebound and improved Kt/V is probably mediated by an increase of intradialysis muscle and systemic blood flow [36]. On the contrary, intradialysis exercise on a cycle ergometer distributed in 15-min intervals during each of the first $3 \mathrm{~h}$ of HD session resulted in an insufficient magnitude of increase in overall Kt/V [14]. Accordingly, we need additional studies of various exercise types and delivery methods to optimize the utilization of intradialysis exercise.

The majority of the mentioned studies were limited to three types of exercise: aerobic exercise, resistance exercise, and combined (aerobic and resistance) exercise. Since most of the evidence exists on the effectiveness of intradialytic aerobic training, it would be beneficial to investigate the effects of different delivery types of exercise, such as home-based, intradialytic, and non-intradialytic exercise. Moreover, physical exercise appears to have inconsistent benefits in HD patients, presumably due to variable intensity and exercise volumes. Consequently, innovative approaches with individualized exercise prescription and lifestyle interventions are needed. Due to a lack of staff who are qualified in prescription and follow-thorough of physical exercise, we should also seek for effective strategies to prepare patients for independent physical exercise in their home environment. The best results may be obtained with the professional dedication of a multidisciplinary team to ensure sustainable physical exercise programs as part of a routine care for HD patients. However, the identification of an optimized, individualized training program is yet to be made.

The present study aimed to determine the effects of functional training and exercise counseling added to the intradialytic cycling program on dialysis adequacy and biochemical parameters in HD patients. Additionally, we aimed to investigate the sustainability and effects of functional exercise transfer to an unsupervised home environment on non-dialysis days and the level of retention of improvements from the first (supervised exercise) study phase.

\section{Methods}

The present prospective, randomized, controlled trial was conducted on 40 voluntary HD patients at HD units of the University Medical Centre in Ljubljana, Slovenia. Patients were randomized from November 2017 to February 2019 into the intervention and control group. Exercise interventions and protocols were described in detail 
previously [37]. The intervention group engaged in guided functional exercise training before each HD session and additional intradialytic cycling exercise in the first 8 weeks. In the second 8 weeks, pre-dialysis functional training was dismissed, and patients were instructed, motivated, and encouraged to perform functional exercise routines at home on non-dialysis days. The exercise program of intradialytic cycling was continued. During both study periods, the control group performed intradialytic cycling only. The flow of the subjects is presented in Fig. 1. The trial compared the effects of the mentioned exercise training strategies on biochemical parameters and dialysis adequacy.

\section{Study criteria and ethical considerations}

The inclusion criteria limited the selection to patients on renal replacement therapy with HD longer than 3 months, age 18-90 years, and a stable medical condition. Exclusion criteria were an infectious or chronic malignant disease, uncontrolled arterial hypertension, angina pectoris grade 2-4 (Canadian Cardiovascular Society), heart failure grade 3 or 4 (New York Heart Association), the presence of a mental disability, limb amputation (two or more fingers on the lower limb and/or on the upper limb). Withdrawal criteria were acute intercurrent illness or trauma that lasted longer than 14 days, the occurrence of malignant disease during the study period, and voluntary withdrawal from the study. National Medical Ethics Committee approval was attained from the Ministry of Health, Republic of Slovenia (approval document number 0120-97/2017-3 KME 68/03/17). All patients signed written informed consent and were informed about the aim, confidentiality, and procedures of the study. The study complies with the Declaration of Helsinki (1964). The study was registered at ClinicalTrials. Gov (Clinicaltrials.gov identifier: NCT03334123).

\section{Study design and outcomes}

The primary study end-point was urea Kt/V per single dialysis episode. Secondary study outcomes were metabolic and inflammatory biochemical parameters. The total length of the intervention was 16 weeks, divided into two phases. Biochemical parameters were assessed at baseline, after 8 weeks, and after 16 weeks at the beginning of each week (Table 2). We assessed albumin, total cholesterol, high-density lipoprotein cholesterol (HDL), low-density lipoprotein cholesterol (LDL), triglycerides (TG), Creactive protein (CRP), and hemoglobin. Levels of each parameter were determined with routine laboratory methods in a local laboratory. Dialysis adequacy $(\mathrm{Kt} / \mathrm{V})$ was determined as the average of measurements at first and at the second dialysis session of the week on the HD machine Fresenius Medical Care (dialysis monitor type $5008^{\circ}$ ). An online clearance monitoring system was used, which measures the $\mathrm{Kt} / \mathrm{V}$ value that corresponds to a single pool $\mathrm{Kt} / \mathrm{V}$ value and is measured by sodium conductivity variation [38]. "V" term (distribution volume for urea) was determined using bioimpedance analysis (Body Composition Monitor ${ }^{\circ}$, Fresenius Medical Care, Bad Homburg, Germany). Kt/V was assessed in the first week, in the 8th week and the 16th week of the intervention.

\section{Interventions description}

After the baseline assessment, the patients were randomized following simple randomization procedures (computerized random numbers) and allocated into the intervention group (INT) or the control group (CON). We allocated patients after baseline assessment and following a list assessed only by the main researcher (and not treating physicians) to avoid selection bias. An overview of the study procedure is shown in Fig. 2. In the first study phase (first 8 weeks), the intervention group attended a guided functional training three times a week before the HD procedure. Besides training, they also received exercise counseling to acquire the functional exercise skills accurately and transfer them to their home environment in the second study phase (second 8 weeks). During the first $2 \mathrm{~h}$ of dialysis, they additionally performed a cycling exercise on the customized bike (Model B'fit Mini, Lemco ${ }^{\circ}$, Denmark). The control group performed the same cycling program as the intervention group without pre-dialysis functional training and counseling.

Functional training was performed for approximately $30 \mathrm{~min}$ before each dialysis session. The intensity was set to 7 th to 8 th grade on a 10 -grade Borg scale. The intradialytic exercise started with 15 min of cycling and was gradually increased in duration (up to $60 \mathrm{~min}$ ) and intensity to maintain the intensity of 4 th to 5 th grade on a 10 -grade Borg scale. Both types of exercise, including exercise counseling, were guided and prescribed by a kinesiologist. Functional training was tailored to the individual's capacity and included exercises with a full range of motion with additional weights. Light cardiovascular, coordination and balance exercises were performed in the warm-up. In the main part of the functional training, patients performed different varieties of lunges, squats, pulls, pushups, lifts, and pushes. The cool-down part included light cardiovascular exercises combined with stretching. Exercise counseling was given at the time of functional training. The patients received instructions on how to correctly perform an exercise, how to modify an exercise, and how to adjust the resistance/load.

In the second phase, the intervention group transferred the pre-dialysis functional training to their home environment. The kinesiologists prepared for each patient written and illustrated exercise program with whom they could track their home exercise and mark the exercises that they performed. The prescribed exercises are listed in Additional file 1. On dialysis days, we 


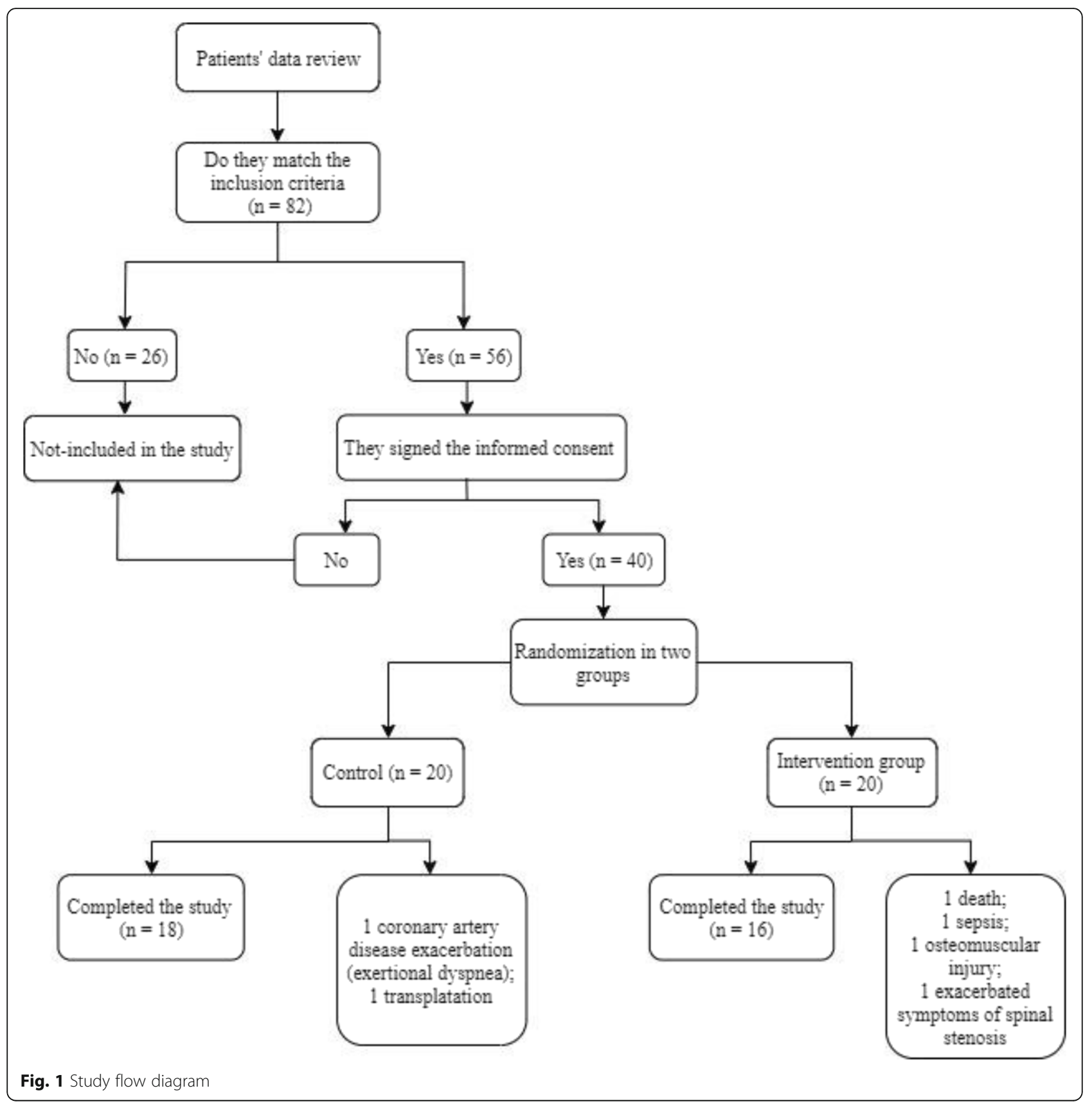

assessed compliance on the basis of their self-report and discussed the issues of home functional exercise, giving feedback, counseling, and motivation. At every dialysis session of the second study phase, they reported the details about the exercise performed during the previous inter-dialysis period. We focused on motivating the patients to stay engaged in the exercise process by discussing the barriers to exercise, setting goals, monitoring safety, and identifying and solving intercurrent problems. Intradialytic cycling program remained the same for both groups during the whole second phase. The kinesiologist and nursing staff monitored patients for complications or adverse effects (e.g., dyspnea, headache, fatigue, chest, muscle, or joint pain) throughout the exercise sessions. Participant blood pressure and heart rate were measured at the beginning and the end of functional training and in the beginning, after $15 \mathrm{~min}$, and immediately after the intradialytic cycling session.

\section{Statistical analysis}

Descriptive statistics (mean $\pm \mathrm{SD}$ ) were calculated for sex, age, weight, height, dialysis vintage, weekly dialysis duration, systolic, and diastolic blood pressure. The independent ttest was used to compare the group's baseline demographic 


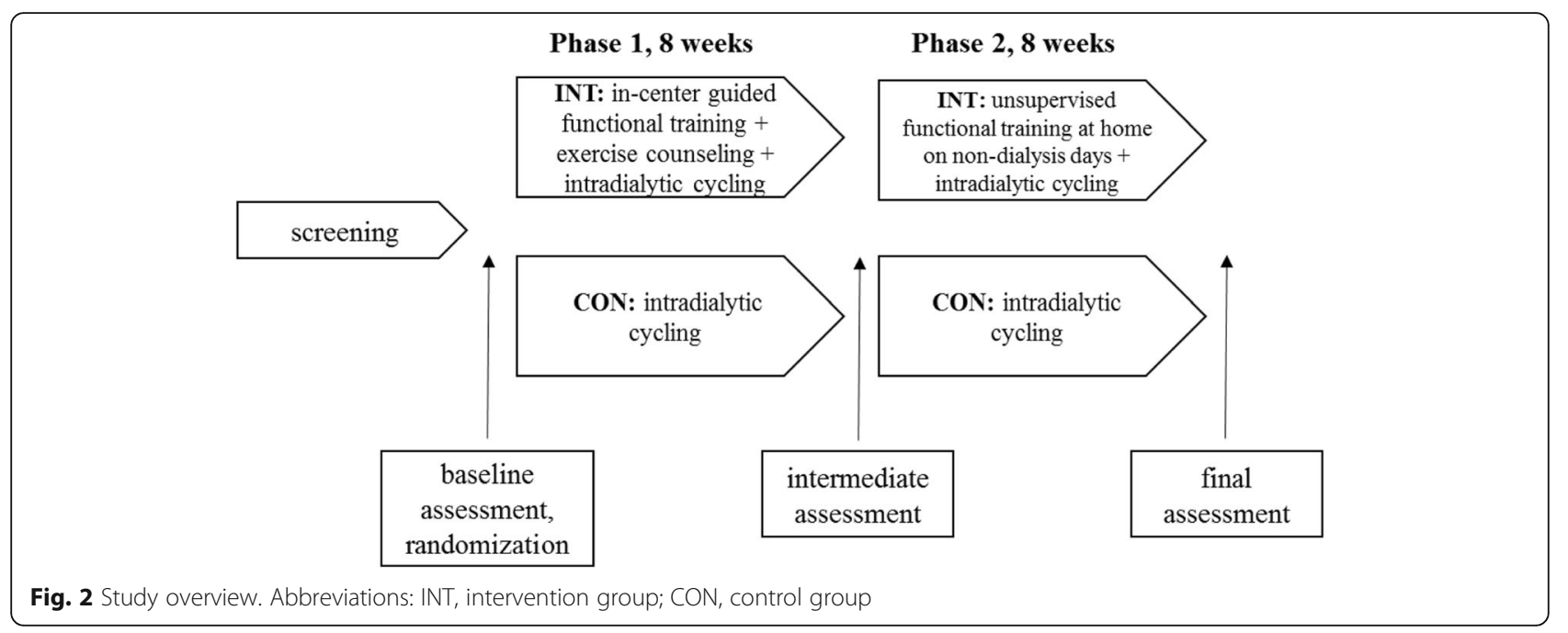

and clinical characteristics. Analysis of covariance (ANCOVA) was used to test for differences between the groups with the baseline value as a covariate. A paired $t-$ test was used to analyze within-group changes over time. We included in analysis all patients available for biochemical parameters assessment, physical performance testing, and $\mathrm{Kt} / \mathrm{V}$ measurement except for injured, hospitalized, transplanted or deceased patients where these measurements were not feasible (for details see Fig. 1). All tests were 2-sided, performed using the SPSS program (version 22; SPSS Inc., Chicago, IL, USA), and assessed at the $p<$ 0.05 level of significance.

\section{Results}

Patients' characteristics and exercise adherence

Table 1 outlines the patients' baseline demographic and clinical characteristics. There were no statistically significant differences between the groups.

Adherence to training programs was defined as the total number of completed exercise sessions in contrast to the total number of sessions offered. In phase 1, adherence of the intervention group for functional training and cycling sessions were $87 \% \pm 12$ and $90 \% \pm 12 \%$, respectively. In the 8 th week, after a gradual increase in duration, the mean intra-dialytic cycling routine duration was $30.5 \pm 8.3 \mathrm{~min}$ for the intervention group and $31.8 \pm 7.8 \mathrm{~min}$ for the control group $(p>0.05)$. In the 16th study week, the intervention group cycled for $46.6 \pm 17.0 \mathrm{~min}$ and control group for $44.4 \pm 12.8 \mathrm{~min}$ $(p>0.05)$. In phase 2 , the intervention group completed $73 \% \pm 21 \%$ of advised at home functional exercise sessions and $82 \% \pm 19 \%$ of in-center cycling sessions. Control group adherence in phase 2 was $82 \% \pm 13 \%$ (cycling sessions). There were no significant between-group differences in intradialytic cycling adherence during either study phases. However, there was a significantly ( $p=$ $0.034)$ lower adherence to home-based functional exercise in contrast to in-center pre-dialysis functional training in the intervention group.

\section{Changes in dialysis adequacy}

Within-group changes in dialysis adequacy $(\mathrm{Kt} / \mathrm{V})$ are presented in Fig. 3. There were no statistically significant differences in blood flow, filter size, and duration of the

Table 1 Comparison of demographic and clinical characteristics between the intervention and control group

\begin{tabular}{llll}
\hline Variable & Intervention group $(n=20)$ & Control group $(n=20)$ & $\boldsymbol{P}$-value \\
\hline Age (years) & $65.2 \pm 12.1$ & $61.9 \pm 13.0$ & 0.43 \\
Male sex (n) & $12(60 \%)$ & $10(50 \%)$ & 0.53 \\
Weight $(\mathrm{kg})$ & $72.6 \pm 16.1$ & $71.7 \pm 15.9$ & 0.42 \\
Height $(\mathrm{cm})$ & $168.4 \pm 9.6$ & $167.5 \pm 10.2$ & 0.42 \\
Dialysis vintage (years) & $7.4 \pm 8.1$ & $7.5 \pm 7.3$ & 0.43 \\
Weekly dialysis duration (h) & $12.5 \pm 2.7$ & $13.3 \pm 1.9$ & 0.43 \\
Systolic blood pressure (mm Hg) & $141 \pm 16.1$ & $144 \pm 14.93$ & 0.50 \\
Diastolic blood pressure (mm Hg) & $78 \pm 10.2$ & $84 \pm 9.38$ & 0.81 \\
\hline
\end{tabular}

Note: Values are expressed as mean \pm SD or number of subjects (percent). Blood pressure was defined as the mean of the last three pre-dialysis blood pressure values. Abbreviations: $n$ number of subjects 


\section{$\mathbf{K t} / \mathbf{V}$}

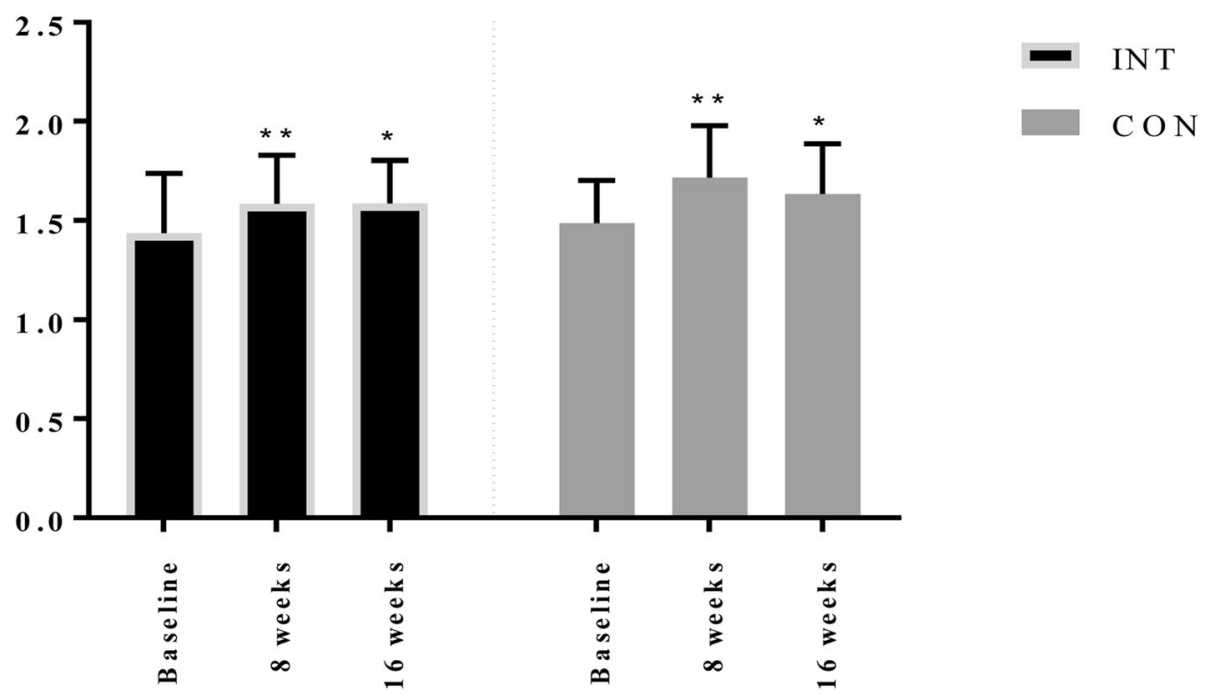

Fig. 3 Within-group changes in Kt $N$ value. Note: ${ }^{*}, p<0.05$ indicates significant within-group difference compared to the baseline value. ${ }^{* *}, p<$ 0.01 indicates significant within-group difference compared to the baseline value. Abbreviations: INT, intervention group; CON, control group; Kt/ $V$, dialysis adequacy

HD session between groups and between study phases (Table 2). Both groups demonstrated a significant increase in urea Kt/V at the 8th and the 16th week of the study compared to their baseline values. Intervention group improved Kt/V from $1.45 \pm 0.25$ to $1.60 \pm 0.24$ at week eight $(0.15 \pm 0.17,95 \%$ CI 0.06 to $0.24 ; p=0.003)$ and to $1.59 \pm 0.22$ at week $16(0.13 \pm 0.2,95 \%$ CI 0.03 to $0.24 ; p=0.017)$. The baseline $\mathrm{Kt} / \mathrm{V}$ value in the control group was $1.51 \pm 0.21$ and raised to $1.72 \pm 0.26$ at week eight $(0.21 \pm 0.18,95 \% \mathrm{CI} 0.11$ to $0.30 ; p<0.001)$ and to $1.64 \pm 0.25$ at week $16(0.13 \pm 0.18,95 \%$ CI 0.03 to 0.22 ; $p=0.013)$. As both groups significantly improved, there was no significant between-group difference in the 8th week (baseline adjusted $p=0.267$ ) and also in the 16th week of the study $(p=0.874)$.

\section{Within-group changes in biochemical parameters}

No significant differences were found for albumin, HDL, triglycerides, CRP, and hemoglobin for both groups at the end of either study phases (Table 3). At week eight, the total cholesterol was significantly lowered in the intervention group $(-0.34 \pm 0.51 \mathrm{mmol} / \mathrm{L}, 95 \% \mathrm{CI}-0.6$ to $-0.07 ; p=0.016$ ) and remained lowered at week 16 $(-0.32 \pm 0.61 \mathrm{mmol} / \mathrm{L}, 95 \%$ CI -0.64 to $-0.01 ; p=$ $0.049)$ with no significant differences in the control group. LDL did not significantly change in the control group; however, intervention group showed a significant decrease in LDL in the 8 th week $(-0.35 \pm 0.56 \mathrm{mmol} / \mathrm{L}$, $95 \% \mathrm{CI}-0.64$ to $-0.06 ; p=0.022)$ and the 16 th week $(-$ $0.28 \pm 0.46 \mathrm{mmol} / \mathrm{L}, 95 \% \mathrm{CI}-0.52$ to $-0.03 ; p=0.030$ ) of the study.

\section{Between-group changes in biochemical parameters}

Baseline adjusted ANCOVA analyses (Table 4) revealed a significant between-group mean difference for LDL in the 16th week of the study. The difference was $-0.35 \pm$ $0.16 \mathrm{mmol} / \mathrm{L}$ (CI $95 \%-0.68$ to -0.03 ) in favor of the intervention group.

\section{Discussion}

The main findings in this study were that 8 weeks of functional training added to intradialytic exercise lowered total cholesterol and LDL in the intervention group while a significant increase in urea $\mathrm{Kt} / \mathrm{V}$ was observed in both groups following 8 and 16 weeks of training, with no difference between both exercise programs. Withingroup changes in cholesterol and urea $\mathrm{Kt} / \mathrm{V}$ were sustained after the transfer of training to an unsupervised home environment.

This study demonstrates that both studied exercise programs improve small solute dialysis adequacy. At the end of the 8th week, patients presented a significant increase in $\mathrm{Kt} / \mathrm{V}$ in both groups. This increase in the $\mathrm{Kt} / \mathrm{V}$ remained significant after 16 weeks in the control group as well as in the intervention group. Exercising during HD procedure leads to an increase in muscle blood flow, with a consequential increase in diffusion area, serum urea clearance and improvement in dialysis adequacy [14]. We speculate that the addition of a functional training did not differ in $\mathrm{Kt} / \mathrm{V}$ improvements from aerobic cycling exercise alone, because the functional exercise was not performed during the dialysis and did not alter these mechanisms. The aforementioned increase in 
Table 2 Dialysis adequacy parameters

\begin{tabular}{|c|c|c|c|c|c|c|c|c|c|}
\hline \multirow[t]{2}{*}{ Group } & \multicolumn{3}{|c|}{ Blood flow (ml/min) } & \multicolumn{3}{|c|}{ Filter size $\left(\mathrm{m}^{2}\right)$} & \multicolumn{3}{|c|}{ Duration of the HD session (min) } \\
\hline & Baseline & 8th week & 16th week & Baseline & 8th week & 16th week & Baseline & 8th week & 16th week \\
\hline INT & $302.8 \pm 8.7$ & $304.4 \pm 18.3$ & $301.7 \pm 15.6$ & $2.0 \pm 0.4$ & $2.0 \pm 0.3$ & $2.1 \pm 0.3$ & $267.8 \pm 31.0$ & $277.2 \pm 30.6$ & $278.9 \pm 27.7$ \\
\hline CON & $287.3 \pm 30.4$ & $293.5 \pm 29.4$ & $289.6 \pm 29.3$ & $1.9 \pm 0.3$ & $1.9 \pm 0.3$ & $1.9 \pm 0.3$ & $277.7 \pm 21.7$ & $277.3 \pm 29.0$ & $267.5 \pm 21.2$ \\
\hline
\end{tabular}

Note: Values are expressed as mean \pm SD. There were no statistically significant differences between groups nor between study phases. Abbreviations: INT intervention group, $\mathrm{CON}$ control group

muscle blood flow during dialysis exercise opens the capillary surface area, consequently increasing the diffusive flux of urea to the vascular compartment [14]. This process increases serum urea clearance and improves dialysis adequacy. Our results agree with the findings of Parsons et al. [14] and Mohseni et al., [39] and demonstrate the benefit in dialytic small solute clearance also with the addition of pre-dialysis training and further with unsupervised training on non-dialysis days as long as the exercise program contains intradialytic exercise. A recent meta-analysis [20] showed improvements in dialysis adequacy following exercise training in HD patients. A single intradialytic cycling session of $60 \mathrm{~min}$ at submaximal exertion improved $\mathrm{Kt} / \mathrm{V}$ by $14 \%$, which is comparable to the effect of $20 \mathrm{~min}$ prolongation of $\mathrm{HD}$ treatment time [36].

Patients in the last stage of chronic kidney disease usually have either normal or increased LDL and decreased levels of HDL [40]. There is clear evidence that lower LDL in population with normal or slightly altered kidney function is beneficial in preventing major cardiovascular risks and mortality [41]. However, in dialysis patients, LDL cholesterol shows a negative association with cardiovascular outcomes at below-average LDL cholesterol levels and a flat or weakly positive association with mortality at higher LDL cholesterol levels [42]. It is known that aerobic exercise can reduce LDL and increase HDL levels in patients on HD [21, 22]. De Moura et al. [23], on the contrary, in a study that included 12 weeks of supervised aerobic exercise training during HD showed an increase in triglycerides and LDL. In the present study, there was a significant decrease in total cholesterol and LDL concentrations in the intervention group, with a significant difference in LDL cholesterol between groups after 16 weeks. While KDOQI guidelines do not advocate de-novo statin therapy for lipid-lowering in dialysis patients [43], this does not extend automatically to lipidlowering with exercise interventions, which provide other important benefits beyond lipid control. It is well documented that the addition of resistance training to aerobic exercise can improve the lipid profile [44]. This was confirmed in a recent study, which showed that interdialytic endurance-resistance training reduced triglycerides and LDL levels and increased HDL [45]. Our findings suggest that with increased volume of exercise in the INT group, there may be a significant effect on total cholesterol and especially on LDL, opposite to a more limited exercise volume in the CON group. Additionally, one study showed that high-load intradialytic resistance training improved lean leg mass in HD patients [46]. Having in mind that cholesterol is associated with skeletal muscles' response [47], it was expected that LDL levels would reduce in the current study. The 0.35 $\mathrm{mmol} / \mathrm{l}$ between-group difference is much smaller than expected with a statin therapy where LDL lowering in the range of $0.85-1.27 \mathrm{mmol} / \mathrm{l}$ difference was found in major trials [42].

This study has some limitations that should be mentioned. First, the sample size was relatively small, which influenced controlling for several factors that may have impacted the results. Second, the intervention was not long enough to tentatively improve some markers of

Table 3 Within-group comparison of biochemical parameters

\begin{tabular}{|c|c|c|c|c|c|c|}
\hline \multirow[t]{2}{*}{ Variable } & \multicolumn{3}{|c|}{ Intervention group } & \multicolumn{3}{|l|}{ Control group } \\
\hline & Baseline & 8th week & 16th week & Baseline & 8th week & 16th week \\
\hline Albumin (g/L) & $39.9 \pm 3$ & $40.2 \pm 3.3$ & $40.0 \pm 2.5$ & $39.5 \pm 2.7$ & $40.3 \pm 3.3$ & $39.9 \pm 3.2$ \\
\hline Cholesterol (mmol/L) & $4.53 \pm 0.91$ & $4.18 \pm 0.95^{*}$ & $4.21 \pm 0.86^{*}$ & $4.23 \pm 1.31$ & $4.06 \pm 1.03$ & $4.24 \pm 1.31$ \\
\hline LDL (mmol/L) & $2.39 \pm 0.77$ & $1.99 \pm 0.81^{* *}$ & $2.12 \pm 0.69^{*}$ & $2.13 \pm 1.12$ & $1.96 \pm 0.79$ & $2.28 \pm 0.92$ \\
\hline $\mathrm{HDL}(\mathrm{mmol} / \mathrm{L})$ & $1.28 \pm 0.46$ & $1.33 \pm 0.62$ & $1.24 \pm 0.38$ & $1.23 \pm 0.48$ & $1.31 \pm 0.53$ & $1.26 \pm 0.52$ \\
\hline TG $(\mathrm{mmol} / \mathrm{L})$ & $1.85 \pm 1.06$ & $1.86 \pm 1.28$ & $2.11 \pm 1.49$ & $2.14 \pm 3.05$ & $1.93 \pm 2.01$ & $1.66 \pm 1.05$ \\
\hline CRP (mg/L) & $4.37 \pm 4.27$ & $3.73 \pm 2.15$ & $4.50 \pm 4.53$ & $4.72 \pm 4.21$ & $4.50 \pm 3.92$ & $6.21 \pm 5.87$ \\
\hline Hemoglobin (g/L) & $118.63 \pm 7.60$ & $117.94 \pm 8.86$ & $117.94 \pm 8.86$ & $122.22 \pm 11.95$ & $118.56 \pm 17.69$ & $118.56 \pm 17.69$ \\
\hline
\end{tabular}

Note: Values are expressed as mean \pm standard deviation. ${ }^{*}, p<0.05$ indicates significant within-group difference compared to the baseline value. ${ }^{*}$, $p<0.01$ indicates significant within-group difference compared to the baseline value. Abbreviations: $L D L$ low-density lipoprotein cholesterol, $H D L$ high-density lipoprotein cholesterol, TG triglycerides, CRP C-reactive protein 
Table 4 The between group difference in biochemical end-points

\begin{tabular}{|c|c|c|c|c|}
\hline \multirow[b]{2}{*}{ Variable } & \multicolumn{2}{|l|}{ 8th week } & \multicolumn{2}{|l|}{ 16th week } \\
\hline & Difference $(95 \% \mathrm{Cl})$ & p-value (INT-CON) & Difference $(95 \% \mathrm{Cl})$ & p-value (INT-CON) \\
\hline Albumin (g/L) & $-0.48 \pm 0.73(-1.97$ to 1.02$)$ & 0.520 & $-0.18 \pm 0.66(-1.51$ to 1.16$)$ & 0.79 \\
\hline Cholesterol (mmol/L) & $-0.11 \pm 0.17(-0.46$ to 0.26$)$ & 0.574 & $-0.23 \pm 0.24(-0.71$ to 0.25$)$ & 0.34 \\
\hline LDL (mmol/L) & $-0.16 \pm 0.16(-0.48$ to 0.17$)$ & 0.339 & $-0.35 \pm 0.16(-0.68$ to -0.03$)$ & $0.03^{*}$ \\
\hline $\mathrm{HDL}(\mathrm{mmol} / \mathrm{L})$ & $-0.03 \pm 0.06(-0.15$ to 0.09$)$ & 0.611 & $-0.05 \pm 0.08(-0.22$ to 0.11$)$ & 0.51 \\
\hline TG (mmol/L) & $0.12 \pm 0.19(-0.28$ to 0.52$)$ & 0.537 & $0.56 \pm 0.33(-0.12$ to 1.24$)$ & 0.11 \\
\hline CRP (mg/L) & $0.53 \pm 0.71(-0.93$ to 1.98$)$ & 0.464 & $-1.18 \pm 2.03(-5.35$ to 2.99$)$ & 0.57 \\
\hline Hemoglobin (g/L) & $0.84 \pm 4.84(-9.03$ to 10.72$)$ & 0.863 & $-0.84 \pm 4.12(-9.24$ to 7.56$)$ & 0.84 \\
\hline
\end{tabular}

Note: Values are expressed as adjusted mean difference \pm standard deviation using ANCOVA - analysis of covariance with adjustment for baseline values. All significant between-group differences with ANCOVA adjusted test were also significant with unadjusted between-group ANOVA test ( $p<0.05$ ). Abbreviations: INT intervention group, CON control group, $L D L$ low-density lipoprotein cholesterol, HDL high-density lipoprotein cholesterol, TG triglycerides, CRP C-reactive protein, $\mathrm{Kt} / \mathrm{V}$ dialysis adequacy, ANCOVA analysis of covariance, $\mathrm{Cl}$ confidence interval; ${ }^{*}, p<0.05$

inflammation. Furthermore, the functional training group had individual attention and additional motivation, which could influence their improvements. There was a lack of an inactive control group to compare between-group differences with functional training group and group who only performed intradialytic cycling. Moreover, we did not measure nutritional intakes in this study, so we were unable to analyse the association of lipid profile or physical performance improvements with differences in each individual's nutritional composition. Observed adverse events during the study were mostly fatigue, joint and low back pain, and isolated hypotension. No major cardiac events and instability in vital signs were observed. Future studies should include larger sample size and longer interventions to be able to see benefits associated with functional training.

\section{Conclusions}

In summary, we demonstrated that 8 weeks of functional training added to intradialytic cycling improved dialysis adequacy and lipid profile. Additionally, the effects of the subsequent unsupervised, home-based program in the functional training group were preserved during the second phase when the transfer of mastered exercise routines to the home environment was done. These data give evidence on the novel exercise prescription strategy by which combined pre-dialysis functional exercise training and intradialytic exercise may increase small solute clearance and, at the same time, reduce cardiovascular risks by improving lipid profile in patients with CKD.

\section{Supplementary information}

Supplementary information accompanies this paper at https://doi.org/10. 1186/s12882-020-02021-2.

Additional file $\mathbf{1}$ Table S1. Exercises prescribed in the functional training program.

\section{Abbreviations}

INT: Intervention group; CON: Control group; HDL: High-density lipoprotein cholesterol; LDL: Low-density lipoprotein cholesterol; TG: Triglycerides; CRP: C-reactive protein; CKD: Chronic kidney disease; HD: Hemodialysis; Kt/ V: Dialysis adequacy; SD: Standard deviation; ANCOVA: Analysis of covariance; n: Number of subjects; Cl: Confidence Interval

Acknowledgments

Not applicable.

\section{Authors' contributions}

Conceptualization was done by JP, and MP. Methodology was performed by JP and ŠB. JP, JBP, and MP validated the study. The investigation was done by ŠB. Resources were guaranteed from JBP and JP. The original draft was written by ŠB. Review and editing was done by JP. JP and JBP supervised the research. All authors read and approved the final manuscript.

Funding

The research was funded by the public Slovenian Research Agency (grant No. L3-1838).

Availability of data and materials

Data generated and analyzed during this study are included in this article. Additional data are available from the corresponding author on request.

Ethics approval and consent to participate

National Medical Ethics Committee approval was attained from the Ministry of Health, Republic of Slovenia (approval document number 0120-97/20173 KME 68/03/17). All patients signed written informed consent and were informed about the aim, confidentiality, and procedures of the study. The study complies with the Declaration of Helsinki.

Consent for publication

Not applicable.

\section{Competing interests}

The authors declare no competing interests.

\section{Author details}

${ }^{1}$ Department of Nephrology, University Medical Centre, 1000 Ljubljana, Slovenia. ${ }^{2}$ University of Ljubljana, Faculty of Sport, 1000 Ljubljana, Slovenia. ${ }^{3}$ University of Ljubljana, Faculty of Medicine, 1000 Ljubljana, Slovenia.

Received: 27 May 2020 Accepted: 13 August 2020

Published online: 18 August 2020

\section{References}

1. Jha V, Garcia-Garcia G, Iseki K, Li Z, Naicker S, Plattner B, et al. Chronic kidney disease: global dimension and perspectives. Lancet. 2013;382:260-72. 
2. Cheng HT, Huang JW, Chiang CK, Yen CJ, Hung KY, Wu KD. Metabolic syndrome and insulin resistance as risk factors for development of chronic kidney disease and rapid decline in renal function in elderly. J Clin Endocrinol Metab. 2012;97:1268-76.

3. Dalrymple LS, Katz R, Kestenbaum B, Shlipak MG, Sarnak MJ, Stehman-Breen $C$, et al. Chronic kidney disease and the risk of end-stage renal disease versus death. J Gen Intern Med. 2011;26:379-85.

4. Beddhu S, Baird BC, Zitterkoph J, Neilson J, Greene T. Physical activity and mortality in chronic kidney disease (NHANES III). Clin J Am Soc Nephrol. 2009:4:1901-6.

5. Bučar Pajek M, Pajek J. Characterization of deficits across the spectrum of motor abilities in dialysis patients and the impact of sarcopenic overweight and obesity. Clin Nutr. 2018;37:870-7. https://doi.org/10.1016/j.dnu.2017.03.008.

6. Hung AM, Chertow GM, Young BS, Carey S, Johansen KL. Inflammatory markers are unrelated to physical activity, performance, and functioning in hemodialysis. Adv Ren Replace Ther. 2003;10:232-40. https://doi.org/10. 1053/j.arrt.2003.10.002.

7. Young HML, March DS, Graham-Brown MPM, Jones AW, Curtis F, Grantham CS, et al. Effects of intradialytic cycling exercise on exercise capacity, quality of life, physical function and cardiovascular measures in adult haemodialysis patients: a systematic review and meta-analysis. Nephrol Dial Transplant. 2018;33:1436-45. https://doi.org/10.1093/ndt/gfy045.

8. Bijlani RL, Vempati RP, Yadav RK, Ray RB, Gupta V, Sharma R, et al. A brief but comprehensive lifestyle education program based on yoga reduces risk factors for cardiovascular disease and diabetes mellitus. J Altern Complement Med. 2005;11:267-74.

9. Wilund KR, Tomayko EJ, Wu P-T, Ryong Chung H, Vallurupalli S, Lakshminarayanan B, et al. Intradialytic exercise training reduces oxidative stress and epicardial fat: a pilot study. Nephrol Dial Transplant. 2010;25: 2695-701. https://doi.org/10.1093/ndt/gfa106.

10. Cheema B, Abas H, Smith B, O'Sullivan A, Chan M, Patwardhan A, et al. Progressive exercise for anabolism in kidney disease (PEAK): a randomized, controlled trial of resistance training during hemodialysis. J Am Soc Nephrol. 2007;18:1594-601.

11. Afshar R, Shegarfy L, Shavandi N, Sanavi S. Effects of aerobic exercise and resistance training on lipid profiles and inflammation status in patients on maintenance hemodialysis. Indian J Nephrol. 2010;20:185-9. https://doi.org/ 10.4103/0971-4065.73442.

12. Liao M-T, Liu W-C, Lin F-H, Huang C-F, Chen S-Y, Liu C-C, et al. Intradialytic aerobic cycling exercise alleviates inflammation and improves endothelial progenitor cell count and bone density in hemodialysis patients. Medicine (Baltimore). 2016;95:e4134. https://doi.org/10.1097/MD.0000000000004134.

13. Fedewa MV, Hathaway ED, Ward-Ritacco CL. Effect of exercise training on C reactive protein: a systematic review and meta-analysis of randomised and non-randomised controlled trials. Br J Sports Med. 2017;51:670-6.

14. Parsons TL, Toffelmire EB, King-VanVlack CE. The effect of an exercise program during hemodialysis on dialysis efficacy, blood pressure and quality of life in end-stage renal disease (ESRD) patients. Clin Nephrol. 2004; 61:261-74 http://www.ncbi.nlm.nih.gov/pubmed/15125032. Accessed 11 Nov 2016.

15. Bogataj Š, Pajek M, Pajek J, Buturović Ponikvar J, Paravlic A. Exercise-based interventions in hemodialysis patients: a systematic review with a metaanalysis of randomized controlled trials. J Clin Med. 2020;9:43. https://doi. org/10.3390/jcm9010043.

16. Bennett PN, Breugelmans L, Agius M, Simpson-Gore K, Barnard B. A haemodialysis exercise programme using novel exercise equipment: a pilot study. J Ren Care. 2007;33:153-8.

17. Jung T-D, Park S-H. Intradialytic exercise programs for hemodialysis patients. Chonnam Med J. 2011;47:61.

18. Miller BW, Cress CL, Johnson ME, Nichols DH, Schnitzler MA. Exercise during hemodialysis decreases the use of antihypertensive medications. Am J Kidney Dis. 2002;39:828-33. https://doi.org/10.1053/ajkd.2002.32004.

19. Goldberg AP, Hagberg J, Delmez JA, Carney RM, McKevitt PM, Ehsani AA, et al. The metabolic and psychological effects of exercise training in hemodialysis patients. Am J Clin Nutr. 1980;33:1620-8.

20. Smart N, McFarlane J, Cornelissen V. The effect of exercise therapy on physical function, biochemistry and dialysis adequacy in Haemodialysis patients: a systematic review and meta-analysis. Open J Nephrol. 2013;03:25-36.

21. Cheema BSB, Singh MAF. Exercise training in patients receiving maintenance hemodialysis: a systematic review of clinical trials. Am J Nephrol. 2005;25:352-64. https://doi.org/10.1159/000087184.
22. Goldberg AP, Geltman EM, Gavin JR, Carney RM, Hagberg JM, Delmez JA, et al. Exercise training reduces coronary risk and effectively rehabilitates hemodialysis patients. Nephron. 1986;42:311-6 http://www.ncbi.nlm.nih. gov/pubmed/3960242. Accessed 30 Dec 2016.

23. De Moura RM, Henrique DMN, De Souza FR, Chaoubah A, Bastos MG, De Paula RB. Exercise training during hemodialysis reduces blood pressure and increases physical functioning and quality of life. Artif Organs. 2010;34:58693. https://doi.org/10.1111/j.1525-1594.2009.00929.x.

24. Gomes Neto M, de Lacerda FFR, Lopes AA, Martinez BP, Saquetto MB. Intradialytic exercise training modalities on physical functioning and healthrelated quality of life in patients undergoing maintenance hemodialysis: systematic review and meta-analysis. Clin Rehabil. 2018;32:1189-202.

25. Johansen KL, Painter P. Exercise in individuals with CKD. Am J Kidney Dis. 2012:59:126-34.

26. Heiwe S, Jacobson SH. Exercise training for adults with chronic kidney disease. In: Heiwe S. Cochrane database of systematic reviews. Chichester: Wiley; 2011. CD003236. doi: https://doi.org/10.1002/14651858.CD003236.pub2.

27. Cheema BSB, Smith BCF, Singh MAF. A rationale for intradialytic exercise training as standard clinical practice in ESRD. Am J Kidney Dis. 2005:45:9126. http://www.ncbi.nlm.nih.gov/pubmed/15861357. Accessed 21 Dec 2016.

28. Johansson P, Dahlström U, Broström A. Factors and interventions influencing health-related quality of life in patients with heart failure: a review of the literature. Eur J Cardiovasc Nurs. 2006;5:5-15.

29. Segura-Ortí E. Ejercicio en pacientes en hemodiálisis: Revisión sistemática de la literatura. Nefrologia. 2010;30:236-46.

30. Smart NA, Titus TT. Outcomes of early versus late nephrology referral in chronic kidney disease: a systematic review. Am J Med. 2011;124:1073-80.

31. Howden EJ, Fassett RG, Isbel NM, Coombes JS. Exercise training in chronic kidney disease patients. Sports Med. 2012;42:473-88.

32. Bogataj Š, Pajek M, Buturović Ponikvar J, Pajek J. Outcome expectations for exercise and decisional balance questionnaires predict adherence and efficacy of exercise programs in dialysis patients. Int J Environ Res Public Health. 2020;17:3175. https://doi.org/10.3390/ijerph17093175.

33. Go AS, Chertow GM, Fan D, McCulloch CE, Hsu C. Chronic kidney disease and the risks of death, cardiovascular events, and hospitalization. N Engl J Med. 2004:351:1296-305. https://doi.org/10.1056/NEJMoa041031.

34. de Palma JR, Bolton CF, Baltzan MA, Baltzan RB. Adequate hemodialysis schedule. N Engl J Med. 1971;285:353-4.

35. Giannaki CD, Stefanidis I, Karatzaferi C, Liakos N, Roka V, Ntente I, et al. The effect of prolonged intradialytic exercise in hemodialysis efficiency indices. ASAIO J. 2011;57:213-8.

36. Kong $\mathrm{CH}$, Tattersall JE, Greenwood RN, Farrington $\mathrm{K}$. The effect of exercise during haemodialysis on solute removal. Nephrol Dial Transplant. 1999;14: 2927-31. https://doi.org/10.1093/NDT/14.12.2927.

37. Bogataj Š, Pajek J, Buturović Ponikvar J, Hadžić V, Pajek M. Kinesiologistguided functional exercise in addition to intradialytic cycling program in end-stage kidney disease patients: a randomised controlled trial. Sci Rep. 2020;10:5717.

38. Kuhlmann U, Goldau R, Samadi N, Graf T, Gross M, Orlandini G, et al. Accuracy and safety of online clearance monitoring based on conductivity variation. Nephrol Dial Transplant. 2001;16:1053-8. https://doi.org/10.1093/ndt/16.5.1053.

39. Mohseni R, Emami Zeydi A, Ilali E, Adib-Hajbaghery M, Makhlough A. The effect of intradialytic aerobic exercise on dialysis efficacy in hemodialysis patients: a randomized controlled trial. Oman Med J. 2013;28:345-9. https:// doi.org/10.5001/omj.2013.99.

40. Gordon L, Pena Y, Lawrence-Wright M, McGrowder D, Cabrera E. Effect of exercise therapy on lipid parameters in patients with end-stage renal disease on hemodialysis. J Lab Physicians. 2012;4:17. https://doi.org/10.4103/ 0974-2727.98665.

41. Massy ZA, De Zeeuw D. LDL cholesterol in CKD - to treat or not to treat? Kidney Int. 2013;84:451-6.

42. Ferro CJ, Mark PB, Kanbay M, Sarafidis P, Heine GH, Rossignol P, et al. Lipid management in patients with chronic kidney disease. Nat Rev Nephrol. 2018;14:727-49.

43. Wanner C, Tonelli M. KDIGO clinical practice guideline for lipid management in CKD: summary of recommendation statements and clinical approach to the patient. Kidney Int. 2014;85:1303-9.

44. Mann S, Beedie C, Jimenez A. Differential effects of aerobic exercise, resistance training and combined exercise modalities on cholesterol and the lipid profile: review, synthesis and recommendations. Sports Med. 2014; 44:211-21. https://doi.org/10.1007/s40279-013-0110-5. 
45. Frih B, Jaafar H, Mkacher W, Ben Salah Z, Hammami M, Frih A. The effect of Interdialytic combined resistance and aerobic exercise training on health related outcomes in chronic hemodialysis patients: the Tunisian randomized controlled study. Front Physiol. 2017;8:288. https://doi.org/10.3389/fphys. 2017.00288.

46. Lopes LCC, Mota JF, Prestes J, Schincaglia RM, Silva DM, Queiroz NP, et al. Intradialytic resistance training improves functional capacity and lean mass gain in individuals on hemodialysis: a randomized pilot trial. Arch Phys Med Rehabil. 2019;100:2151-8.

47. Riechman SE, Andrews RD, MacLean DA, Sheather S. Statins and dietary and serum cholesterol are associated with increased lean mass following resistance training. J Gerontol Ser A. 2007;62:1164-71. https://doi.org/10. 1093/gerona/62.10.1164

\section{Publisher's Note}

Springer Nature remains neutral with regard to jurisdictional claims in published maps and institutional affiliations.

Ready to submit your research? Choose BMC and benefit from:

- fast, convenient online submission

- thorough peer review by experienced researchers in your field

- rapid publication on acceptance

- support for research data, including large and complex data types

- gold Open Access which fosters wider collaboration and increased citations

- maximum visibility for your research: over $100 \mathrm{M}$ website views per year

At $\mathrm{BMC}$, research is always in progress.

Learn more biomedcentral.com/submissions 